\title{
The effectiveness of positive thinking training on self- efficacy and emotion regulation in men with hemophilia
}

\author{
Masoumeh Beiranvand ${ }^{1}$, Majid Keramati Moghadam ${ }^{2 *}$, Reza Sabounchi ${ }^{3}$, Mahmoud Delphan ${ }^{4,5}$, Azam Ghafuori ${ }^{6}$ and Roghayeh Keramati \\ Moghadam ${ }^{7}$ \\ ${ }^{1}$ Department of Psychology, Faculty of Social Sciences, Imam Khomeini International University, Qazvin, Iran \\ ${ }^{2}$ Department of Sport Management, Faculty of Physical Education and Sport Sciences, Islamic Azad University Borujerd Branch, Borujerd, Iran \\ ${ }^{3}$ Faculty of Physical Education and Sport Sciences, Islamic Azad University Borujerd Branch, Borujerd, Iran \\ ${ }^{4}$ Young Researchers and Elite Club, Sciences and Researches Branch (Oloom Tahghighat Branch), Islamic Azad University, Tehran, Iran \\ ${ }^{5}$ Department of Physical Education and Sport Sciences, Faculty of Humanities, Tarbiat Modares University, Tehran, Iran \\ ${ }^{6}$ Departments of Educational Psychology, Candidate, Faculty of Psychology and Education, Allameh Tabataba'i University,Tehran, Iran \\ ${ }^{7}$ Faculty of Management, Islamic Azad University Central Tehran Branch, Tehran, Iran
}

\begin{abstract}
Study design: A semi-experimental study (pre-test, post-test, and follow-up with the control group).

Summary and background data: Hemophilia as an inherited bleeding creates fundamental changes in the quality of life of hemophiliac population. Patients with hemophilia need to improve the positive relationship with themselves and others by a positive thinking training and the avoidance of negative thoughts as a coping strategy against the problems of their life.
\end{abstract}

Objectives of the study: The purpose of this study was to examine the effectiveness of positive thinking training on self-efficacy and emotion regulation in men with hemophilia.

Method: In the present study, 30 patients with hemophilia were selected among all patients with hemophilia (N=129) of Lorestan province. They were randomly assigned to the experimental group $(\mathrm{N}=15)$ and control group $(\mathrm{N}=15)$. The subjects completed self-efficacy and emotion regulation questionnaires. Seligman's positive thinking training program was administered to the experiment group in eight 120-minute sessions and the control group received no training. The collected data were analyzed using Covariance statistics method and SPPS software (version 21).

Results: The results of this study showed that the self-efficacy and emotion regulation increased significantly in the experimental group when compared to control group.

Conclusion: The positive thinking training helps patients with hemophilia to avoid negative thoughts and apply better strategies to cope effectively with problems. Patients' information processing works more efficiently by positive thinking and it increases self-efficacy and emotion regulation.

\section{Introduction}

Hemophilia is an inherited bleeding disorder, which is one of the most costly diseases in the world. There is no plasma protein, responsible factor for blood clotting, in this disease. Hemophilia characterized by deficiency of coagulation factor 8 (also known as hemophilia A or classic hemophilia) and coagulation factor 9 (also known as hemophilia B or Christmas disease) [1,2]. Hemophilia $\mathrm{A}$ and $\mathrm{B}$ are due to the congenital deficiency of clotting factor VIII and LX. Therefore, women are carriers of hemophilia and men with hemophilia. Hence, this disease is related to the gender. It means that the defective gene located on chromosome $\mathrm{x}$ that causes the disease in males and females are a hereditary carrier $[3,4]$. Undoubtedly, the experience of Hemophilia creates fundamental changes in one's life, because the patient is in a position to deals with many psychosocial, emotional and physically problems accommodate. While self-efficacy as a person's source of coping can facilitate the process of adaptation to these changes [5]. Self-efficacy is the main structure of Bandura's social and cognitive theory. Performance is called individuals' judge about their capability, capacity, and capabilities to perform a specific task and to conclude designed levels [6]. Emotional reactions that involve in stress are required emotion regulation. The increasing of selfefficacy is associated with the behavior change, treatment acceptance, and the promotion of physical and mental health [7]. According to the results of the last few decades in the field of a central role of emotional experiences in the escalation of hemophilia, the researchers studied the effects of emotion regulation in the consequences of the disease. The capacity of excitation control human capacity is important for a human's adaptation [8]. The emotion regulation is as processes that individuals evaluate their emotions through them and it helps to determine what type of emotional reactions are appropriate that are expressed in a right

${ }^{*}$ Correspondence to: Majid Keramati Moghadam, Department of Sport Management, Faculty of Physical Education and Sport Sciences, Islamic Azad University Borujerd Branch, Borujerd, Iran, Tel: +99166638717; E-mail: majid.keramatimoghadam@gmail.com

Key words: positive thinking, self-efficacy, emotion regulation, hemophilia

Received: June 7, 2019; Accepted: July 12, 2019; Published: July 15, 2019 
time and an appropriate manner [9]. Emotional responses can affect physical health. There is a special attention in this context to the role of hostility, anxiety, and depression in the field of hemophilia and the core of the findings is that the increasing of negative emotions levels is associated with the worsening of Hemophilia disease. Accordingly, researchers believe that emotion regulation may be involved in the consequences of this disease [10]. The concept of emotion regulation refers to the processes that people use consciously or unconsciously to respond appropriately to environmental applications. This structure plays a significant role in mental health and disease. The successful emotion regulation is associated with the health promotion [11]. A new approach known as positive psychology tries to deals with positive issues of human's life such as emotion regulation and self-efficacy with a scientific and practical look in the last decade [12]. Positive psychology is a term that has been created in the response to overemphasis of psychological on problems and disease. This approach does not ignore those problems that people may experience but it believes that the focused attention to disorders will lead to a defective vision of the human's condition and position [13]. Positive thinking is the result of individuals' attitude to life and its periphery phenomena and in fact, it is a mirror that shows the individuals' insight practices and attitudes to the creation and God's creatures [14]. The results of Ben Zur's (study showed that a positive thinking had a positively relationship with health and it could play a positive role in health [15]. Positive thinking training may be as effective as physical activity and exercise training [16-20] on improving health-related quality of life among patients and health population. In addition, it can use as a priceless tool to improve psychological parameters in healthy and unhealthy people $[12,21]$. Hence, the positive thinking training seems to be invaluable plan for hemophilia patients to improve the positive relationship with themselves and others so that they can feel good about themselves and to have valuable and positive relationships with others and to control emotions. In general, a positive thinking and the avoidance of negative thoughts are more effective strategies to cope with problems. The good mood improves patients' information processing effectively and increases emotion regulation and self- efficacy [22]. Self-efficacy and emotion regulation studies to clear the positive thinking training effects on hemophiliac population are poorly understood. It was necessary to evaluate understanding of mental health issues related to patients with hemophilia and the planning for the treatment of these issues in order to possibly enhanced self-efficacy, the reduction of incompetence sense and negative emotions, the emotional proper draining, improvement of interpersonal relationships and emotion regulation Therefore, this study was conducted to examine the effectiveness of positive thinking training on self-efficacy and emotion regulation in men with hemophilia.

\section{Materials and methods}

\section{Study design}

This study was semi-experimental research with pre-test and posttest and follow-up design, using control group.

\section{Subjects}

All men who were a member of Hemophilia Association of Lorestan province $(\mathrm{N}=129)$ were population of investigate. Then, 30 patients with hemophilia were randomly selected from this population. Written informed consent was obtained by all participants. Finally, they were randomly assigned to the experimental group $(\mathrm{N}=15)$ and the control group $(\mathrm{N}=15)$.

\section{Instruments and tasks}

The instrument of this study was included Gross and John's Emotion Regulation Questionnaire and Scherer's Self-Efficacy Questionnaire. Gross and John's emotion regulation questionnaire consists of two sub-scales: reappraisal with 6 items and suppression with 4 items. The subjects answered by 7 point Likert scale from strongly agree (score 1) to strongly disagree (score 7). The internal correlation was 0.79 for the reappraisal subscale and 0.73 for the suppression subscale in Gross and John's study [10]. It is also reported 0.79 for the rate of Cronbach's alpha coefficient in the reappraisal subscale [23]. Scherer's self-efficacy questionnaire had 17 questions that each question was regulated on the basis of Likert's scale from strongly disagree to strongly agree. The scale scoring was in this way that each question was awarded from 1 to 5 points. 1, 3, 8, 9, 13, and 15 questions were scored from right to left and the rest of the questions were scored from left to right. Therefore, a subject's the maximum score was 85 and his minimum score was 17 . The reliability coefficient of scale was 0.76 using the Guttman's split-half test and 0.70 using Cronbach's alpha coefficient [24].

\section{Procedure}

The experimental group were trained under positive thinking training for 8 sessions of 2 hours. The control group did not receive any training during this period. Therefore, the training program was included 8 training sessions of 2 hours that was conducted twice a week for a month. Seligman's positive thinking training as a treatment program was an adoption of Seligman's et al2006 positive thinking training that was prepared for use in this study [25]. The content of the training sessions is summarized as follows:

The first session: (introduction and direction) Subjects' familiarity with the training period and concepts such as life satisfaction, happiness, vitality, and the role of these factors in a good life and ways of achieving a satisfying life, the assessment of life satisfaction, happiness, the meaning in life and individuals' depression, and the training of homework: the positive self-introduction.

The second session: (personal empowerments and the use of them in a new form (the accomplishment of personal empowerment questionnaire and the identification of each member's five premier empowerments in the group, the introduction of personal empowerments as a way to achieve life satisfaction, and the training of homework: the use of empowerments in a new form.

The third session: (the planting of positive emotions and the mention of blessings and good things in life) the familiarity with positive emotions and their role in the vitality and happiness, the mention of blessings and the positive things in daily life, the survey of amount of use of personal empowerments in individuals' behavior and the familiarity with positive emotions, and the presentation of homework: the mention of three positive things / three blessings in life.

The fourth session: (the personal legacy and the intention and purpose in life) the review of the task of previous session, the discussion about the importance of having purpose and meaning in life with referring to the symptoms of depression in individuals, the description of personal legacy personal and its application in life, the presentation of questions in the field of personal legacy to respond until the next session.

The fifth session: (the gratitude letter and visit (appreciation and thanks), and the survey of half training course) the survey of the 
results of activities that are done during the previous weeks, the on the good memories, the move to the creation of appropriate interpersonal communication, the increasing of satisfaction of life through the pleasure of satisfy others, the training of art appreciation and gratitude, the implementation of all tests of the first session, and homework: the implementation of technique of letter writing and the gratitude visit.

The Sixth session: (positive social relationships and happiness in life) the introduction to positive social relations, the role of positive relationships in life, happily, the training and the provision of homework: the application of technique of constructive and active respond.

The seventh session: (work with contemplation and calm (the avoidance precipitance)) the familiar with how to stabilize pleasures, work with reflection and calm and its role in life satisfaction and the presentation of provide homework: how to work with contemplation

The eighth session: (the happiness celebration and the stabilization of happiness) the feedback of training course, the holding of happiness celebration, the implementation of conducted tests in the first session, the study of follow-up of training effects in the next month.

\section{Data analysis}

The collected data were analyzed using Covariance statistics method. The covariance statistics method was used to determine the effect of pre-test variable (positive thinking training) on the dependent variable (post-test scores of self-efficacy and emotion regulation). Also, the assumption of homogeneity of regression slopes and variances were surveyed before the covariance analysis. Levene's test was used to survey the assumption of homogeneity of variances. Furthermore, the Kolmogorov-Smirnov test was used to determine the normal distribution of scores in two variables. SPSS statistical software (version 21) were used to statistically analyze all data. Its significance level was set at $\mathrm{P}<0.05$. All data presented as mean $\pm \mathrm{SD}$ as well.

\section{Results}

All frequency data has shown in Tables 1-4. In addition descriptive variable are presented in Table 5.

Table 1. The frequency distribution of demographic characteristics of the sample

\begin{tabular}{|l|c|c|c|}
\hline Groups & Education & F & Percent \\
\hline \multirow{5}{*}{ The experimental group } & Diploma & 7 & $46.7 \%$ \\
\hline \multirow{5}{*}{ The control group } & Associate's degree & 1 & $6.7 \%$ \\
\cline { 2 - 4 } & Bachelor's degree & 4 & $26.7 \%$ \\
\cline { 2 - 4 } & Master's Degree & 3 & $20 \%$ \\
\hline \multirow{5}{*}{ Total } & Diploma & 8 & $53.3 \%$ \\
\hline & Associate's degree & 1 & $6.7 \%$ \\
\hline & Bachelor's degree & 4 & $26.7 \%$ \\
\hline & Master's Degree & 2 & $13.3 \%$ \\
\hline & Diploma & 15 & $50 \%$ \\
\hline & Associate's degree & 2 & $6.7 \%$ \\
\hline & Bachelor's degree & 8 & $26.7 \%$ \\
\hline & Master's Degree & 5 & $16.7 \%$ \\
\hline
\end{tabular}

Table 2. The frequency distribution of demographic characteristics of the sample

\begin{tabular}{|l|c|c|c|}
\hline Groups & Marital status & F & Percent \\
\hline \multirow{2}{*}{ The experimental group } & Married & 5 & $33.3 \%$ \\
\cline { 2 - 4 } & Single & 10 & $66.7 \%$ \\
\hline \multirow{2}{*}{ The control group } & Married & 4 & $26.7 \%$ \\
\hline \multirow{2}{*}{ Total } & Single & 11 & $73.3 \%$ \\
\hline & Married & 9 & $30 \%$ \\
\cline { 2 - 4 } & Single & 21 & $70 \%$ \\
\hline
\end{tabular}

Table 3. The frequency distribution of demographic characteristics of the sample

\begin{tabular}{|l|c|c|c|}
\hline Groups & Employment status & F & Percent \\
\hline \multirow{3}{*}{ The experimental group } & Self-Employed & 5 & $33.3 \%$ \\
\cline { 2 - 4 } & Employee & 7 & $46.7 \%$ \\
\cline { 2 - 4 } & Unemployed & 3 & $20 \%$ \\
\hline \multirow{3}{*}{ The control group } & Self-Employed & 6 & $40 \%$ \\
\cline { 2 - 4 } & Employee & 5 & $33.3 \%$ \\
\hline \multirow{3}{*}{ Total } & Unemployed & 4 & $26.7 \%$ \\
\hline & Self-Employed & 11 & $36.7 \%$ \\
\hline & Employee & 12 & $40 \%$ \\
\hline & Unemployed & 7 & $23.3 \%$ \\
\hline
\end{tabular}

Table 4. The frequency distribution of demographic characteristics of the sample

\begin{tabular}{|c|c|c|c|}
\hline Age & Experimental group & Control group & Total \\
\hline Number & 15 & 15 & 30 \\
\hline Mean & 31.67 & 30.07 & 30.87 \\
\hline SD & 6.10 & 7.96 & 7.02 \\
\hline Middle & 31 & 31 & 31 \\
\hline Minimum & 18 & 18 & 18 \\
\hline Maximum & 41 & 45 & 45 \\
\hline
\end{tabular}

Table 5. The results of descriptive indicators of variables

\begin{tabular}{|c|c|c|c|c|c|}
\hline variables & & Groups & Number & Mean & SD \\
\hline \multirow{6}{*}{ Self-efficacy } & \multirow{2}{*}{ Pre-test } & Experimental & 15 & 64 & 9.21 \\
\hline & & Control & 15 & 60.33 & 9.44 \\
\hline & \multirow{2}{*}{ Post-test } & Experimental & 15 & 71.73 & 6.02 \\
\hline & & Control & 15 & 62.73 & 10.86 \\
\hline & \multirow{2}{*}{ Follow up } & Experimental & 15 & 69.60 & 5.73 \\
\hline & & Control & 15 & 61.33 & 10.34 \\
\hline \multirow{6}{*}{$\begin{array}{l}\text { Emotion } \\
\text { regulation }\end{array}$} & \multirow{2}{*}{ Pre-test } & Experimental & 15 & 50.07 & 8.32 \\
\hline & & Control & 15 & 44.47 & 5.50 \\
\hline & \multirow{2}{*}{ Post-test } & Experimental & 15 & 55.47 & 7.45 \\
\hline & & Control & 15 & 43.07 & 6.85 \\
\hline & \multirow{2}{*}{ Follow up } & Experimental & 15 & 53.20 & 7.80 \\
\hline & & \begin{tabular}{|l|} 
Control \\
\end{tabular} & 15 & 43.20 & 6.52 \\
\hline
\end{tabular}

The results of homogeneity of regression slopes showed (Table 6) a lack of interaction between group and pre-test scores, in the posttest and follow up phases. Therefore, this assumption was confirmed and regression slopes were homogeneous (self-efficacy variable: posttest: $\mathrm{F}=3.82$, P-value $=0.06$, Follow up: $\mathrm{F}=3.60$, P-value=0.07; emotion regulation variable: post-test: $\mathrm{F}=3.53, \mathrm{P}$-value $=0.07$; Follow up: $\mathrm{F}=1.89$, P-value=0.18).

The results showed that that there was no difference between variances of two group in the pre-test and follow up phases (Table 7). Therefore, this assumption was confirmed (the result of Levene's test for self-efficacy variable: post-test: $F=2.65, P$-value $=0.11$, Follow up: $\mathrm{F}=1.56, \mathrm{P}$-value $=0.22$; emotion regulation variable: post-test: $\mathrm{F}=0.40, \mathrm{P}$ value $=0.53$; Follow up: $\mathrm{F}=0.57$, P-value $=0.45$ ).

According to the results of Table 8 , the obtained statistics were smaller than the critical value at 0.95 (1.96). Hence, the scores distribution were closed to the normal distribution and there had no significant difference with it.

The results in Table 9 showed that the random variable (pre-test) had a significant relationship with dependent variables (post-test and follow up). There was a significant factor effect between subjects in selfefficacy variable (Post-test: $\mathrm{F}=9.66$, follow up: $\mathrm{F}=8.56$ ) and in emotion regulation variable (Post-test: $\mathrm{F}=23.25$, follow up: $\mathrm{F}=12.91$ ) after the adjustment of pre-test scores. Therefore, the results showed that there was a significant difference between post-test and follow up scores in 
Table 6. The assumption of homogeneity of regression slopes

\begin{tabular}{|l|l|l|l|l|l|l|}
\hline \multicolumn{2}{|l|}{ Variance Sources } & "SS & df & *MS & F & Sig \\
\hline \multirow{2}{*}{ Self-efficacy } & Post-test & 78.87 & 1 & 78.87 & 3.82 & 0.06 \\
\cline { 2 - 8 } & Follow up & 58.80 & 1 & 58.80 & 3.60 & 0.07 \\
\hline \multirow{2}{*}{ Emotion regulation } & Post-test & 52.38 & 1 & 52.38 & 3.53 & 0.07 \\
\cline { 2 - 7 } & Follow up & 22.74 & 1 & 22.47 & 1.89 & 0.18 \\
\hline
\end{tabular}

"Sum of squares; *Mean square

Table 7. The results of assumption of homogeneity of variances

\begin{tabular}{|r|c|c|c|c|c|}
\hline \multicolumn{2}{|c|}{ Variables } & F & Df $_{1}$ & Df $_{2}$ & Sig \\
\hline \multirow{2}{*}{ Self-efficacy } & Post-test & 2.63 & 1 & 28 & 0.11 \\
\cline { 2 - 6 } & Follow up & 1.56 & 1 & 28 & 0.22 \\
\hline \multirow{2}{*}{ Emotion regulation } & Post-test & 0.40 & 1 & 28 & 0.53 \\
\cline { 2 - 6 } & Follow up & 0.57 & 1 & 28 & 0.45 \\
\hline
\end{tabular}

Table 8. The assumption of normal distribution of scores

\begin{tabular}{|c|l|c|c|}
\hline \multirow{2}{*}{ Self-efficacy } & Variables & Kolmogorov- Smirnov test & Sig \\
\hline \multirow{2}{*}{ Emotion regulation } & Post-test & 0.67 & 0.75 \\
\cline { 2 - 4 } & Follow up & 0.68 & 0.73 \\
\cline { 2 - 4 } & Post-test & 0.57 & 0.89 \\
\cline { 2 - 4 } & Follow up & 0.49 & 0.96 \\
\hline
\end{tabular}

Table 9. The results of covariance analysis related to the life expectancy and coping skills

\begin{tabular}{|c|c|c|c|c|c|c|c|c|}
\hline variable & "DV & ${ }^{\# \mathrm{CS}}$ & $*$ SS & df & $* * \mathbf{M S}$ & $\mathbf{F}$ & Sig & $* \# \mathbf{E}$ \\
\hline \multirow{4}{*}{ Self-efficacy } & \multirow{2}{*}{ Post-test } & Pre-test & 1377.5 & 1 & 1377.5 & 47.4 & 0.01 & 0.63 \\
\hline & & Group & 280.74 & 1 & 280.74 & 9.66 & 0.01 & 0.26 \\
\hline & \multirow{2}{*}{ Follow up } & Pre-test & 1231.2 & 1 & 1231.2 & 45.6 & 0.01 & 0.62 \\
\hline & & Group & 230.37 & 1 & 230.77 & 8.56 & 0.01 & 0.24 \\
\hline \multirow{4}{*}{ Emotion regulation } & \multirow{2}{*}{ Post-test } & Pre-test & 996.79 & 1 & 996.79 & 61.4 & 0.01 & 0.69 \\
\hline & & group & 277.12 & 1 & 277.12 & 23.5 & 0.01 & 0.46 \\
\hline & \multirow{2}{*}{ Follow up } & Pre-test & 1113.8 & 1 & 1113.8 & 89.8 & 0.01 & 0.76 \\
\hline & & Group & 160.14 & 1 & 160.14 & 12.9 & 0.01 & 0.32 \\
\hline
\end{tabular}

"Dependent variable; ${ }^{\# \#}$ Change source; *Sum of squares; **Mean square, **Effect size of Eta

two groups. In addition, the results showed that the rate of self-efficacy and emotion regulation increased in the experimental group after the conducted courses of positive thinking training.

\section{Discussion}

The aim of the present study was to examine the effectiveness of positive thinking training on self-efficacy and emotion regulation in men with hemophilia. The results of this study showed that positive thinking intervention resulted in increased significantly self-efficacy in men with hemophilia. We confirmed the outcomes of the previous studies that were on the basis of effectiveness of positive thinking training on self-efficacy [26,27]. Positive thinking training can increase the possible of more positive personal impressions of own increases resulted in that the people to be able to accept more responsibility for their validity and to achieve a full understanding of themselves. Researchers believe that positive thinking plays an important role to cope with stressful events of life $[28,29]$. Positive people have the confidence and stability when they are faced with a challenge (even if progress is difficult or slow), but the pessimists are hesitant and unstable. This difference may be more in difficult circumstances such as hemophilia disease. Positive patients believe that hardness can run a successful manner. This difference in attitude toward hardness and disease affects hemophilia patients' self-efficacy [30]. On the other hand, the findings of the present study demonstrated that the positive thinking training had the beneficial effects on emotion regulation. These results are confirmed by other evidence $[31,32]$.
We can acknowledge in the analysis and interpretation of this part of the study that emotion and behavior interact with each other. The emotion regulation with control of attention and emotional-cognitive consequences cause to change altering cognitive systems function (such as memory, attention, awareness) and then emotion regulation. In the other words, emotion regulation has a major effect on mental health, motivational processes and appropriate response to the problems in daily life as one of human's the important psychological aspects and affect individuals' various actions. Although emotions have a biological basis, people are able to influence the intensity, duration and type of their emotional experiences.

\section{Conclusion}

The positive thinking training as an essential strategy and high value approach may count as an important tool to tackle with stressful situations of life and consequently leads to improve health and peace of spirit and mind in society. The results of this study may use in counseling centers, mental health clinics, etc. Therapists can encourage others using positive psychology strategies, which can help them to understand and improve patients' strengths.

\section{Acknowledgment}

We thank all hemophiliac men who participated in this project.

\section{Conflict of interest}

The authors declare no conflict of interest.

\section{References}

1. Srivastava A, Brewer AK, Mauser-Bunschoten EP, Key NS, Kitchen S, et al. (2013) Guidelines for the management of hemophilia. Haemophilia 19: e1-47. [Crossref]

2. Fijnvandraat K, Cnossen MH, Leebeek FW, Peters M (2012) Diagnosis and management of haemophilia. BMJ 344: e2707. [Crossref]

3. Mazloum V, Khayabash K, Rahnama N (2013) Comparing the effects of therapeutic exercise and hydrotherapy on pain severity and knee range of motion in patients with hemophilia: a randomized controlled trial. Armaghane Danesh 18: 430-441.

4. Mazloum V, Rahnama N, Khayambashi K (2014) Effects of therapeutic exercise and hydrotherapy on pain severity and knee range of motion in patients with hemophilia: a randomized controlled trial. International Journal of Preventive Medicine 5: 83.

5. Schwarzer R, Boehmera S, Luszczynskab A, Mohamedc NE, Knoll N (2005) Dispositional self-efficacy as a personal resource factor in coping after surgery. Personality and Individual Differences 39: 807-818.

6. Damirchi I, Ghazi F, Shishegeran S (2016) The comparison of cognitive emotion regulation, locus of control, and search for meaning in drug-dependent women and usual women. Journal of Women and Society 7: 129-146.

7. Bandura A (1986) Social foundations of thought and action. Englewood Cliffs, NJ.

8. Ochsner KN, Gross JJ (2005) The cognitive control of emotion. Trends Cogn Sci 9: 242-249. [Crossref]

9. Wang M, Saudino KJ (2011) Emotion regulation and stress. Journal of Adult Development 8: 95-103.

10. Gross JJ (2013) Emotion regulation: taking stock and moving forward. Emotion 13 359.

11. Aldao A, Nolen-Hoeksema S, Schweizer S (2010) Emotion-regulation strategies across psychopathology: A meta-analytic review. Clinical Psychology Review 30: 217-237.

12. Ghiasi SE, Tabatabaee TS, Nasri M (2016) Effect of optimism training on emotion regulation and psychological well-being in undergraduate students of university of Birjand, in 2014-2015. Pajouhan Scientific Journal 14: 27-37.

13. Seligman ME, Csikszentmihalyi M (2014) Positive psychology: An introduction, in flow and the foundations of positive psychology. Springer, pp: 279-298.

14. Parsa A (2013) The effect of positive thinking training on mental health in female high school students of Tehran, in faculty of humanities, MA thesis, Payame Noor University, Tehran, Iran. 
15. Ben-Zur H (2012) Loneliness, optimism, and well-being among married, divorced, and widowed individuals. J Psychol 146: 23-36. [Crossref]

16. Delphan M, Alinejad HA, Delfan M, Dehghan S (2017) Intratumoral effects of continuous endurance training and high intensity interval training on genes expression of miR-21 and bcl-2 in breast cancer bearing female mice. Iranian Quarterly Journal of Breast Diseases, 2017. 10(2): p. 49-57.

17. Ghareghani P, Shanaki M, Ahmadi S, Khoshdel AR, Rezvan N, et al. (2017) Aerobic endurance training improves nonalcoholic fatty liver disease (NAFLD) features via miR-33 dependent autophagy induction in high fat diet fed mice. Obesity Research \& Clinical Practice.

18. Delphan M, Rashidlamir A, Delphan F (2012) Resting plasma agrp levels response to exercise-conjugated diet and only diet. Biology of Sport 29: 45-50.

19. Delphan M, Rashidlamir A, Delfan F, Izadpanah N, Rahbarizade F. The effects of two weight loss protocol onresting plasma concentration of IL-6 inoverweight and obese health sedentaryfemale of college students. 22nd International Congress on Pediatrics.

20. Delphan M, Rashidlamir A, Ebrahimi-Atri A, Saadatnia A (2013) The effect of two weight loss protocols on plasma concentration of agouti related peptide (AgRP) in elite wrestlers. Jundishapur Scientific Medical Journal 12: 229-41.

21. Dargahi S, Mohsenzade F, Zahrakar K (2015) The effect of positive thinking training on psychological well-being and perceived quality of marital relationship on infertile women.

22. Shafiei K (2009) The survey of effectiveness of positive thinking skills training in group form on the reduction of test anxiety and anger control in male guidance students of public schools in Jiroft city in faculty of physical education and sport sciences. Marvdasht Islamic Azad university Mashhad, Iran.
23. Bigdeli I, Najafy M, Rostami M (2013) The relation of attachment styles, emotion regulation, and resilience to well-being among students of medical sciences. Iranian Journal of Medical Education 13: 721-729.

24. Shamaei Zadeh M, Abedi MR (2005) The effect of job consultation on the increasing of self-efficacy of students' entrepreneurship in University of Isfahan. Knowledge and Research in Applied Psychology 7: 29-38.

25. Seligman ME, Rashid T, Parks AC (2006) Positive psychotherapy. American Psychologist 61: 774 .

26. Mostafaei A, Mohammadi A (2016) Investigating the effect of positive self-talking on self-efficacy in elemen-tary male students.

27. Moghimian M, Karimi T (2013) The effect of group positive self- talk and relaxation techniques training and their combination on social anxiety of nursing students. Iran Journal of Nursing 26: 66-75.

28. Sang G, Valcke M, van Braak JM Tondeur J (2010) Student teachers' thinking processes and ICT integration: Predictors of prospective teaching behaviors with educational technology. Computers and Education 54: 103-112.

29. Seligman ME (2002) Positive psychology, positive prevention, and positive therapy Handbook of Positive Psychology 2: 3-12.

30. Poursardar N, Poursardar F, Panahandeh A, Sangari A, Zarrin SA (2013) Effect of optimism on mental health and life satisfaction: A psychological model of well-being.

31. Fredrickson BL (2000) Cultivating positive emotions to optimize health and wellbeing. Prevention and Treatment $3: 1 \mathrm{a}$.

32. Carver CS (2014) Self-control and optimism are distinct and complementary strengths Personality and Individual Differences 66: 24-26.

Copyright: $\odot 2019$ Beiranvand M. This is an open-access article distributed under the terms of the Creative Commons Attribution License, which permits unrestricted use, distribution, and reproduction in any medium, provided the original author and source are credited. 